\title{
Acetylcholine and attention
}

Citation for published version (APA):

Klinkenberg, I., Sambeth, A., \& Blokland, A. (2011). Acetylcholine and attention. Behavioural Brain Research, 221(2), 430-442. https://doi.org/10.1016/j.bbr.2010.11.033

Document status and date:

Published: 01/01/2011

DOI:

10.1016/j.bbr.2010.11.033

Document Version:

Publisher's PDF, also known as Version of record

Document license:

Taverne

Please check the document version of this publication:

- A submitted manuscript is the version of the article upon submission and before peer-review. There can be important differences between the submitted version and the official published version of record.

People interested in the research are advised to contact the author for the final version of the publication, or visit the DOI to the publisher's website.

- The final author version and the galley proof are versions of the publication after peer review.

- The final published version features the final layout of the paper including the volume, issue and page numbers.

Link to publication

\footnotetext{
General rights rights.

- You may freely distribute the URL identifying the publication in the public portal. please follow below link for the End User Agreement:

www.umlib.nl/taverne-license

Take down policy

If you believe that this document breaches copyright please contact us at:

repository@maastrichtuniversity.nl

providing details and we will investigate your claim.
}

Copyright and moral rights for the publications made accessible in the public portal are retained by the authors and/or other copyright owners and it is a condition of accessing publications that users recognise and abide by the legal requirements associated with these

- Users may download and print one copy of any publication from the public portal for the purpose of private study or research.

- You may not further distribute the material or use it for any profit-making activity or commercial gain

If the publication is distributed under the terms of Article $25 \mathrm{fa}$ of the Dutch Copyright Act, indicated by the "Taverne" license above, 


\section{Review}

\section{Acetylcholine and attention}

\section{Inge Klinkenberg*, Anke Sambeth, Arjan Blokland}

Faculty of Psychology and Neuroscience, Department of Neuropsychology and Psychopharmacology,

European Graduate School of Neuroscience (EURON), Maastricht University, PO Box 616, 6200 MD Maastricht, The Netherlands

\section{A R T I C L E I N F O}

\section{Article history:}

Received 30 August 2010

Received in revised form

15 November 2010

Accepted 16 November 2010

Available online 23 November 2010

\section{Keywords:}

Cognition

Lesion

Microdialysis

Muscarinic

Nicotinic

Imaging

\begin{abstract}
A B S T R A C T
Historically, ACh has been implicated in learning and short-term memory functions. However, more recent studies have provided support for a role of cortical ACh in attentional effort, orienting and the detection of behavioral significant stimuli. The current review article summarizes studies in animals and humans which have investigated the role of ACh in attention and cognition. An attempt has been made to differentiate between brain regions involved in attentional processes versus those important for other cognitive functions. To this purpose, various experimental methods and interventions were used. Animal behavioral studies have injected the selective immunotoxin IgG-saporin to induce specific cholinergic lesions, employed electrochemical techniques such as microdialysis, or have administered cholinergic compounds into discrete parts of the brain. Human studies that give some indication on the link between central cholinergic signaling and cognition are obviously confined to less invasive, imaging methods such as fMRI. The brain areas that are deemed most important for intact attentional processing in both animals and humans appear to be the (pre)frontal, parietal and somatosensory (especially visual) regions, where ACh plays a vital role in the top-down control of attentional orienting and stimulus discrimination. In contrast, cholinergic signaling in the septohippocampal system is suggested to be involved in memory processes. Thus, it appears that the role of ACh in cognition is different per brain region and between nicotinic versus muscarinic receptor subtypes.
\end{abstract}

(c) 2010 Elsevier B.V. All rights reserved.

\section{Contents}

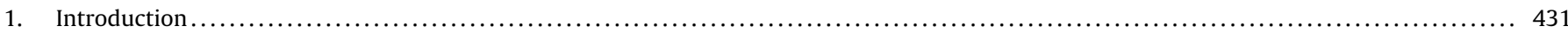

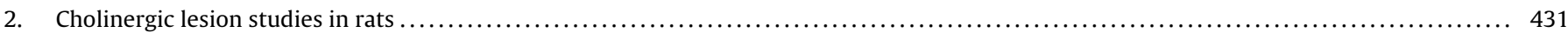

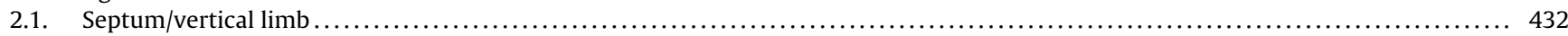

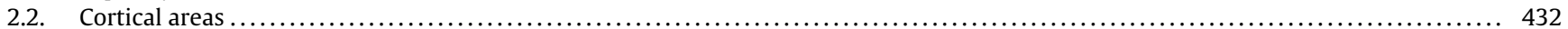

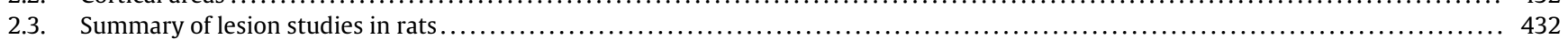

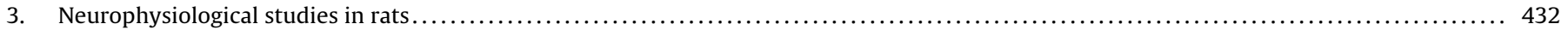

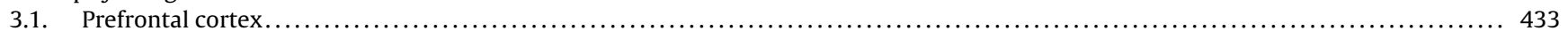

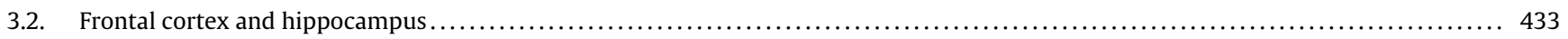

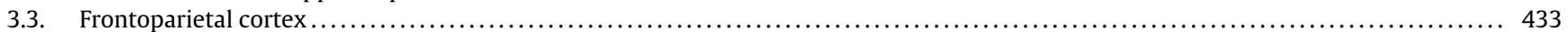

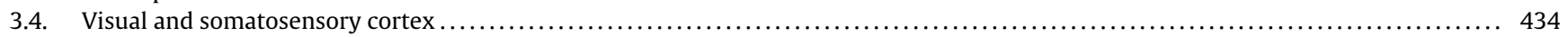

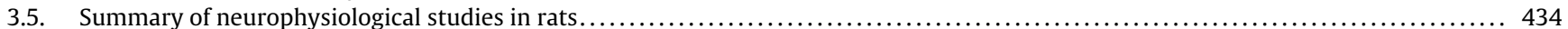

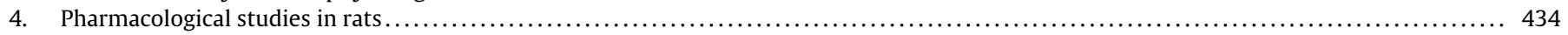

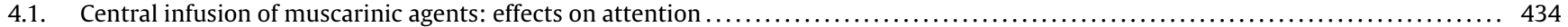

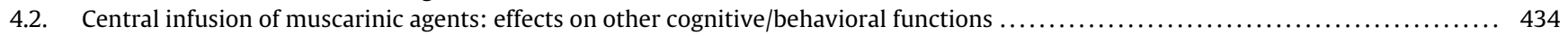

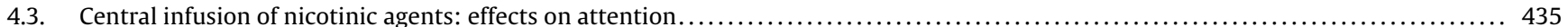

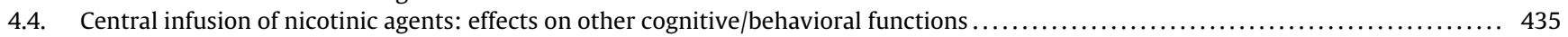

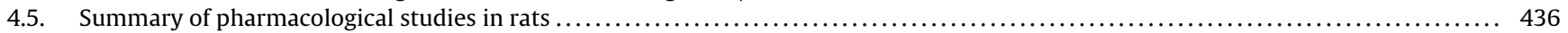

Abbreviations: ACh, acetylcholine; mPFC, medial prefrontal cortex; 5-CSRTT, 5-choice serial reaction time task; VI, variable interval; adlFC, anterodorsal lateral frontal cortex; IPC, intraparietal cortex; MLA, methyllycaconitine; DH $\beta E$, dihydro- $\beta$-erythroidine; DRN, dorsal raphé nucleus; fMRI, functional magnetic resonance imaging.

* Corresponding author. Tel.: +31 43388 4217; fax: +31433884560.

E-mail addresses: inge.klinkenberg@maastrichtuniversity.nl (I. Klinkenberg), anke.sambeth@maastrichtuniversity.nl (A. Sambeth), a.blokland@maastrichtuniversity.nl (A. Blokland). 


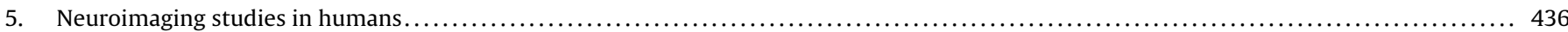

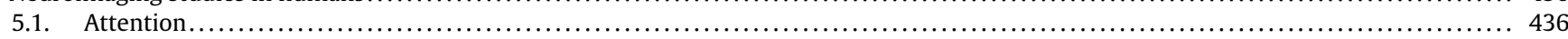

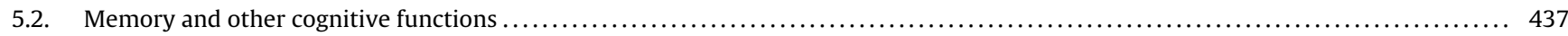

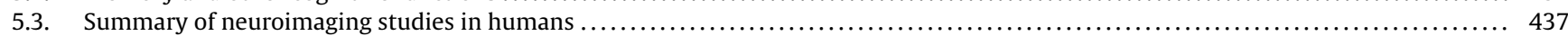

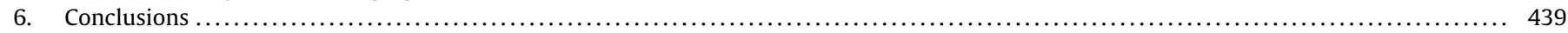

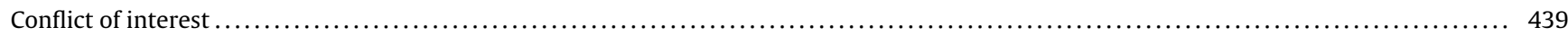

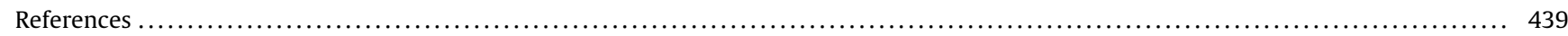

\section{Introduction}

Since the first publications of Bartus et al. [1,2] acetylcholine (ACh) has been claimed playing a critical role in cognitive functions, especially learning and memory. Research with Alzheimer disease patients and experimental manipulations in animals (cholinergic lesions and drug studies) provided further support for the notion that ACh is involved in learning and memory. A vast amount of experimental studies showed learning and memory impairments in a wide variety of tasks after compromising the cholinergic system using muscarinic or nicotinic antagonists and after lesioning cholinergic cells concluding that ACh was involved in memory functions. Of note, the effects were most prominent in short-term memory and working memory tasks [3]. These data provided further support for the cholinergic hypothesis of memory dysfunction and fueled the development of cholinergic drugs for treating memory disorders. At present, cholinesterase inhibitors (and the NMDA antagonist memantine) are the only approved drugs for treating cognitive impairments in Alzheimer's disease. However, it must be noted that the effects of cholinesterase inhibitors are limited and associated with various side effects [4,5]. Despite this limited success of cholinesterase inhibitors in treating cognitive function in dementia, recent drug development programs still concentrate on cholinergic targets, like the nicotinic receptor [6-8] and the muscarinic type 1 receptor $[9,10]$. Thus, ACh is still considered as an important neurotransmitter involved in cognitive functions.

During the last decade the role of ACh in cognitive functions has been refined [11-15]. In contrast to a general role in learning and memory recent studies provide also support for a role of cortical ACh in attention (more specifically: attentional effort and orienting) and detection of behavioral significant stimuli [16-18]. These more recent insights have become available by means of novel behavioral tests, development of toxins for selective cholinergic lesions, tools for measuring phasic ACh release and for pharmacologically altering central cholinergic neurotransmission.

To give a first example, a highly specific toxin was developed (i.e., 192-IgG-saporin) that was very selective for cholinergic cells [19]. The principle of this toxin was based on the unique property of cholinergic neurons which contain the p75 low affinity nerve growth factor receptor. By using the conjugate of the non-selective toxin saporin with a carrier that binds to the nerve growth factor receptor, a selective lesion of the cholinergic system could be achieved. This enabled investigating the function of lowered ACh levels in the brain and even in selective brain areas.

Further, selective drugs for receptor subtypes (i.e. muscarinic and nicotinic) became available allowing a differentiation of the cholinergic system on a receptor level. In addition, an increasing number of studies examined the effects of intracerebral injections of these selective cholinergic drugs. These studies provided a more detailed picture of the role of cholinergic receptors in specific brain areas. Moreover, novel microdialysis techniques allow for the investigation of changes in ACh efflux on a much smaller timescale. Finally, more sophisticated behavioral tests became available for testing the specificity of the cholinergic manipulation on various cognitive domains, attentional functions in particular. Taken together, all these developments contributed to a better understanding of the role of the cholinergic system in cognitive functions.
The current review provides a summary of animal and human experiments which have assessed the role of ACh in particular brain regions in attentional processes. First, an overview will be given of the studies in which the effects of selective cholinergic lesions were examined. Next, a summary will be made of studies investigating neurophysiological changes (e.g., in ACh release) in several behavioral paradigms. Further, we will discuss studies in which drugs were locally applied in animals. Finally, an attempt will be made to relate the findings in animals to those reported in human imaging studies examining the role of cholinergic signaling in particular brain regions in attentional functions. We will show that the role of the cholinergic system in relation to cognitive functions cannot be regarded as a whole. Rather, the role of cholinergic neurotransmission in cognitive function is dependent on the particular brain region which is targeted. On the basis of these findings the role of ACh in attention will be discussed.

\section{Cholinergic lesion studies in rats}

The early studies investigating the cholinergic system used nonselective tools (e.g., ibotenic acid quinolinic acid, AMPA) to lesion cholinergic neurons in the basal forebrain in rodents. This was a non-optimal choice because of the diffuse spread of cholinergic cells in rodents in the nucleus basalis. Thus, these excitotoxic lesions also affected all neurons containing glutamatergic receptors, making it very difficult to interpret the effects in terms of a specific cholinergic deficit. The development of the selective cholinergic immunotoxin 192-IgG-saporin was a major breakthrough in this field [19]. This toxin showed highly selective lesions of cholinergic neurons with no or marginal effects on GABAergic and glutamatergic neurons [20]. Although remarkable selective and substantial decreases in cholinergic markers were reported, the expected clear effects in learning and memory tasks were no longer found [15]. Thus, lesions of the basal forebrain cholinergic neurons led to a profound decrease of cholinergic markers but the first studies applying this toxin did not report lesions effects in spatial learning and memory tasks [20-22]. Of note, some studies reported learning and memory deficits after saporin lesions but these were likely to be caused by lesions of the cerebellar Purkinje cells after intracerebroventricular infusions [23].

More recent studies have discussed other issues with interpreting the effects of 192-IgG-saporin lesions on cognition. For example, it was discussed that the extent of the lesion may explain some inconsistency between data [24]. Thus, it was argued that lesions which include the diagonal band of Broca and septum may lead to more non-specific effects as compared to lesions that are limited to the nucleus basalis [24]. It was noted that on basis of the information in the publications it was difficult to verify the extent of the lesion and the relation with the dose of 192-IgG-saporin (of note, the effects might also depend on the batch of the toxin).

Another interesting finding from different studies was that selective cholinergic lesions of the nucleus basalis did not impair spatial learning in the Morris water escape task [20,21,25,26]. Interestingly, effects on learning and memory were found in studies in which non-aversive tests were used [27-29]. Based on the aversive nature of various tasks, one study showed that a pre-test saline injection attenuated the 192-IgG-saporin lesion effect on learning 
[30]. On basis of these data it was proposed that aversive stimulation may attenuate the cholinergic lesion-induced performance deficits.

The selectivity of 192-IgG-saporin has also been questioned. For example, some studies reported learning and memory deficits when this toxin was infused intracerebroventricularly [23]. Later on these effects were contributed to lesions of cerebellar Purkinje cells which also contain the p75 low affinity nerve growth factor receptor [31]. Consequently, the effects of intracerebroventricular infusions should be treated with great caution since lesions of Purkinje cells could account for the learning and memory deficits [23]. It should be mentioned that this effect is less relevant when infusing 192-IgG-saporin into cortical and subcortical structures.

A further drawback of 192-IgG-saporin was that it did not cause dramatic cholinergic lesions in mice. Because the use of a selective cholinergic lesion would be interesting for studying cholinergic deficits in transgenic mice, a mouse variant of the immunotoxin saporin was developed. Despite some initial problems, a mu p75-saporin toxin was developed that could be infused intracerebroventricularly [32,33]. In mice mu p75-saporin lesions were also reported to impair learning and memory functions which could not be attributed to lesions of cerebellar Purkinje cells. At present no studies are available in which the selective cholinergic lesions in mice on attentional functions were investigated.

A recent review showed that the effect of cholinergic manipulation on behavioral functions is dependent on the brain region [3]. Therefore, studies in which the immunotoxin 192-IgG-saporin is injected into distinct brain/cortical regions or nuclei that project to selective areas are of great value for obtaining a better understanding of the cognitive functions of the cholinergic system in different brain regions. In this respect, the effects of basal forebrain lesions are less relevant since lesioning of these cholinergic cells leads to global cortical cholinergic deficits and may not allow dissociating the different functions of cortical regions.

\subsection{Septum/vertical limb}

Studies in which the immunotoxin was injected into the septal area in combination with the vertical limb of the diagonal band, a procedure mainly destroying cholinergic projections to the hippocampus, revealed effects of treatment in the acquisition of a delayed matching to position T-maze task [28]. Further it was found that these lesions impaired the processing of the conditioned stimulus [34]. This was shown by a lack of a latent inhibition effect in lesioned animals and was interpreted in terms of an attentional deficit. In another study it was shown that retention of spatial location in a Morris task was impaired after septal plus vertical limb of the diagonal band lesions [35]. However, it should be noted that these effects were found when a test-retest of 25 , and not 1 or 5 , days was used. In a radial water maze lesioned rats were not impaired in acquiring the task and only showed a mild impairment when switching from a cue to a spatial task [25]. In a cone field task only a mild effect on working- and reference memory performance was found [27]. The speed of cone visits was faster in rats with septal lesions, which was interpreted in terms of impaired attention (i.e., preferring speed over accuracy) or increased motivation (i.e., increased rewarding effect of the food pellets). No effects of immunotoxin lesions were found in a water radial arm maze in which the memory load was increased [22]. An evaluation of the effects in a behavioral test battery showed a lesion effect in a delayed non-matching to position task but not in a Morris water escape task [20]. In addition to these subtle effects, septal lesions increased behavioral activity in rats as shown by elevated nocturnal activity [20,27].

\subsection{Cortical areas}

Several studies evaluated the effects of 192-IgG saporin after infusion in distinct cortical areas, although it should be mentioned that the number of these studies is limited. Experiments in which lesions were made in the prefrontal areas showed that attentional performance decreased [36] and in addition also increased impulsive responding [37]. The effects of posterior parietal cholinergic lesions were evaluated in two associative learning paradigms [38]. It was found that the lesioned animals were impaired when the degree of attentional processing was increased but not in learning the associative value of the stimuli. On basis of these data it was concluded that the posterior parietal cortex cholinergic system is involved in the change of attentional processing for relevant cues.

One study examined the effects of selective cholinergic lesions of the cingulate cortex in a conditional visual discrimination task [39]. The lesioned rats were impaired in learning the conditional rule, also at asymptotic performance. The asymptotic deficit was specifically related to a deficit in responding to the fast stimulus condition whereas no lesion effect was found in the condition in which the rule was associated with a slow stimulus. It was suggested that the cholinergic system of the cingulate cortex is involved in taskrelevant stimulus processing. A final study that investigated the effects of a selective cortical lesion tested the effects of cholinergic depletion of the entorhinal cortex [40]. The rats were tested in an odor task (delayed non-matching-to-sample) in which the rats had to discriminate between novel and familiar odors. Interestingly, the lesioned animals were not impaired in this task when they had to discriminate between familiar odors but were impaired when they had to discriminate between novel odors. These data showed that the cholinergic innervation of the entorhinal cortex is involved in working memory for novel stimuli.

\subsection{Summary of lesion studies in rats}

Some differentiation between the functions of the cholinergic system in cortical regions can be found. In all, the effects of septal lesions on learning and memory performance are mixed. Although no robust effects were found in standard learning and memory tests, different studies revealed subtle effects in different tasks. Mostly, these effects were interpreted in terms of attentional deficits, but the effects of septal lesions have not been evaluated in attention tests yet. Attentional functions are most strongly implicated for the prefrontal and posterior parietal regions. The cingulate cortex appears to be involved in conditional learning whereby the cholinergic innervation seems to be involved in task relevant stimulus processing. This may be related to effects seen after posterior parietal lesions which affected the changes in attention required for increased stimulus processing. The role of entorhinal cortex cholinergic system differs from these deficits. The cholinergic system in this cortical region appears to be involved in working memory for novel stimuli.

\section{Neurophysiological studies in rats}

Experiments in which tonic ACh release has been measured in vivo in moving animals have indicated that the link between cholinergic signaling and attentional performance is more complex than suggested by lesion studies. For instance, increases in ACh efflux have been observed after transfer to an operant chamber associated with performance of a sustained attention task [41], exposure to darkness [42], anticipation and consumption of a palatable meal [43], elevated motor activity [44,45], animal handling and drug administration [46]. It is possible that these elevated extracellular ACh levels after routine experimental procedures are due to 
a taxing of the animals' attentional abilities. Nevertheless, it is difficult differentiating between genuine, task-related $\mathrm{ACh}$ increases and those caused by non-specific testing conditions. Clearly, microdialysis studies need to take these factors into account in their study design in order to be able to make definitive conclusions regarding attentional task-related elevations in ACh efflux (for recommendations see [47]).

Of note, with the exception of the study by Parikh et al. [16], the temporal resolution of the microdialysis techniques that have been used in the studies mentioned below is limited; a single data point represents ACh release collected over several minutes [48]. Therefore, these results reflect tonic rather than phasic changes in ACh efflux, which would be consistent with ACh acting as a neuromodulator regulating arousal instead of a fast-responding synaptic neurotransmitter involved in attention [49]. However, Parikh and Sarter [48] have argued that the predominant view of cholinergic neurotransmission as tonic and slow-acting is too restrictive and they have stated that, with the use of new microdialysis techniques which are capable of measuring changes in ACh efflux on the scale of seconds, we should be able to come to a better understanding of the relation between tonic and phasic ACh release (i.e., on multiple timescales) and attentional functions

\subsection{Prefrontal cortex}

Several studies using microdialysis tools have focused on the relation between $\mathrm{ACh}$ release in the prefrontal cortex and attentional performance. For instance, Passetti et al. [50] reported increases in medial prefrontal cortical ( $\mathrm{MPFC}$ ) ACh during performance of a 5-choice serial reaction time task (5-CSRTT) relative to baseline. At a 5-s stimulus duration, there was a correlation between mPFC ACh efflux and the number of completed trials. However, increasing the attentional demands of the task by means of shortening the stimulus duration did not lead to changes in ACh release. These results were replicated and extended by Dalley et al. [51] who showed elevated ACh release in the prelimbic PFC region in rats performing the 5-CSRTT relative to animals which received a non-contingent version of the task. A study by Parikh et al. [16] is the first one which assessed both tonic and phasic changes in $A C h$ release in relation to attention. Using a cue detection task, a relation between $\mathrm{MPFC} A \mathrm{Ch}$ and behavioral performance was demonstrated. Detection of behaviorally relevant cues increased phasic (i.e., on the scale of seconds) mPFC ACh efflux whereas missed cues evoked a reverse pattern in cholinergic activity. Interestingly, pre-cue ACh levels trends were associated with larger phasic ACh amplitude and better cue detection performance. Fast, phasic changes in ACh levels were superimposed on slower, tonic alterations, suggesting that $\mathrm{ACh}$ release operates on multiple timescales.

An earlier study by Himmelheber et al. [47] assessed whether mPFC ACh release could be induced by operant test paradigms that do not explicitly tax attentional functions. Rats performed a visual discrimination task and a variable interval (VI) schedule of reinforcement during which interference was introduced by means of a flashing house light. Standard testing was followed by an extinction session. MPFC ACh release did not change relative to baseline during any of these task manipulations. It was concluded that operant tasks which assess habit-based forms of responding do not require mPFC cholinergic neurotransmission. Moreover, this would point towards a role of $\mathrm{ACh}$ in attentional abilities instead of sensory, motivational or motor processes.

\subsection{Frontal cortex and hippocampus}

The relationship between frontal and/or hippocampal ACh release and behavior has mostly been assessed using non- attentional paradigms. For instance, Acquas et al. [52] assessed whether presentation of visual and auditory cues would induce changes in frontal and hippocampal cholinergic signaling in animals which were fear conditioned, habituated or naive to these stimuli. Presentation of these cues induced increases in frontal and hippocampal ACh efflux in the fear conditioned and novel stimuli groups, but not in the habituation group (independent of stimulus modality). They concluded that increments in frontal and hippocampal cholinergic neurotransmission appear to be produced by the occurrence of behaviorally important stimuli. Since both the frontal cortex and hippocampus are innervated by cholinergic projections from the basal forebrain, these findings would provide support for a role of the basal forebrain in attentional functions. Moreover, the results of Acquas et al. [52] were in line with those of a more recent study by Nail-Boucherie et al. [53] that reported elevated hippocampal ACh levels in rats which were exposed to a context associated with foot shock as compared to animals which were not fear conditioned. Hata et al. [54] investigated the link between hippocampal ACh activation and performance in a negative patterning and an elemental discrimination paradigm. The elevation in hippocampal ACh was higher during the negative patterning task as compared to the elemental discrimination task, which was explained by the relatively higher difficulty level and hence the higher attentional demands of this paradigm.

Introducing animals to novel sensory stimuli and/or novel environments has also generally yielded elevations in PFC and hippocampal ACh release. For example, handling of animals was found to increase cholinergic activity in the lateral precentral area of the frontal cortex, which was most pronounced if animals were returned to their home cage instead of introduced to an open field [55]. Of note, in the nucleus accumbens core and shell, cholinergic activity was also increased, but there was no difference in nucleus accumbens ACh release in animals exposed to an open field vs. animals that were returned to their home cage. Another study by Inglis and Fibiger [56] demonstrated that ACh release after sensory stimulation is dependent on modality and brain region. Exposure to auditory, olfactory, tactile but not visual stimuli evoked increases in frontal cortical ACh efflux. In contrast, visual, auditory, tactile but not olfactory stimuli were shown to elicit ACh release in the hippocampus. In an additional experiment by Giovannini et al. [57] first time exploration of a novel environment elevated cholinergic activity in frontal cortex and hippocampus, which was not correlated with motor activity. When the animals were introduced to the arena a second time, cholinergic activity was again increased in both brain areas. However, the elevation was not as pronounced as compared to that during the first exploration but was positively correlated with motor activity. It was concluded that ACh release during exposure to a novel environment is related to motor activity on the one hand, and related to attention, anxiety and fear on the other hand. In familiar environments, ACh release appears to be only related to motor activity.

\subsection{Frontoparietal cortex}

Several experiments have assessed the relation between frontoparietal cholinergic activity and behavioral performance in attention paradigms. Transfer of the animals to the testing chamber has generally been reported to already elevate frontoparietal ACh release. Performance in an sustained attention task was found to increase ACh efflux even more [58,59]. Manipulating the demands on attention has not consistently been accompanied by changes in ACh release. For example, Himmelheber et al. [59] demonstrated that within-task switches to low attentional performance parameters did not evoke changes in frontoparietal ACh efflux. In contrast, recovery of behavioral performance after introduction of a visual distractor led to further increases of ACh efflux, i.e., beyond those 
already induced by the sustained attention task [58]. Moreover, frontoparietal cholinergic activity in sustained attention tasks has been found to be higher as compared to ACh release induced by control tasks that assess sensorimotor and motivational aspects of operant performance $[59,60]$.

\subsection{Visual and somatosensory cortex}

A number of studies have looked into the effects of attention and cholinergic signaling on sensory processing. An experiment by Goard and Dan [17] assessed the effect of nucleus basalis stimulation on V1 cortical neurons. They reported that nucleus basalis activation enhanced sensory representation of natural stimuli via muscarinic-dependent decorrelation and increased reliability of V1 neural responses. These results would be consistent with a role of cholinergic signaling in the nucleus basalis in increasing perceptual encoding during attention. Fournier et al. [61] demonstrated that ACh release in (somato)sensory areas is modality-specific; visual stimulation in anesthetized rats enhanced ACh efflux in visual cortex whereas skin stimulation increased somatosensory ACh activation. This would point towards a region- and modality-specific influence of ACh release in the basal forebrain to cortical areas instead of widespread, diffuse activation.

\subsection{Summary of neurophysiological studies in rats}

Several microdialysis experiments have suggested that the degree of attentional effort (i.e., the degree to which task parameters tax attentional operations) rather than attentional performance predicts increases in cortical ACh release [58,62]. Furthermore, on basis of studies on $\mathrm{ACH}$ release under various experimental circumstances some differentiation between brain regions can be made. Cholinergic signaling in (pre)frontal and frontoparietal areas appears to be most strongly implicated in attentional processes. A role of the cholinergic system in the hippocampus in attention can at this point not be excluded, yet evidence is mostly indirect (i.e., use of non-attentional behavioral paradigms) and there exists an extensive tremendous amount of studies and models indicating that the hippocampus is involved in mnemonic functions [63]. In visual areas such as V1, ACh is important for attentional modulation of perceptual encoding. In frontal, hippocampal, visual and somatosensory areas, ACh efflux appears to be region- and modality-specific. This would characterize the basal forebrain ACh signaling to cortical areas as fast-responding (i.e., phasic) influencing attentional functions specifically for each brain region, rather than inducing diffuse (i.e., tonic) neuromodulatory changes in general cortical arousal levels.

\section{Pharmacological studies in rats}

Experiments which have used central infusion of cholinergic compounds into discrete brain regions in order to assess the effect of these treatments on attentional paradigms are unfortunately relatively sparse. An additional approach has been to use central injection of muscarinic or nicotinic antagonists as a means of deducing the role of a particular brain region in behavioral paradigms measuring non-attentional functions such as short-term memory or stimulus discrimination. Thus, strong evidence from pharmacological experiments suggesting a link between cholinergic signaling in particular brain regions and attention performance is lacking. Nevertheless, an attempt will be made to summarize the results of these studies in order to be able to indicate in which brain regions cholinergic neurotransmission appears to be implicated in attentional vs. other cognitive functions. Of note, studies using intracerebroventricular infusion of compounds will not be included, as it is difficult to deduce in which brain areas cholinergic neurotransmission is affected.

\subsection{Central infusion of muscarinic agents: effects on attention}

Two studies assessed the effects of central administration of scopolamine on attentional orienting [64] and 5-CSRTT performance [65], respectively. Robbins et al. [65] infused scopolamine locally into the $\operatorname{mPFC}(3,6$, and $10 \mu \mathrm{g} /$ site unilaterally) and anterodorsal lateral frontal cortex (adlFC; 2.5 and $5 \mu \mathrm{g} /$ site bilaterally) in rats subjected to a 5-CSRTT paradigm. They showed that the highest doses of scopolamine $(10 \mu \mathrm{g} /$ site unilaterally for $\mathrm{mPFC}$ and $5 \mu \mathrm{g} /$ site bilaterally for adlFC) reduced accuracy and increased response latency in the 5-CSRTT. The number of omissions was increased after scopolamine administration in the adlFC ( 2.5 and $5 \mu \mathrm{g} /$ site bilaterally), whereas in the MPFC site no changes in omission responses were noted. There were also no changes in premature or perseverative responding after drug treatment. The authors concluded that cholinergic neurotransmission in both the mPFC and the adlFC areas is implicated in attentional performance but not impulsive behavior. Moreover, the adlFC site could also be important for sensorimotor responding.

Davidson and Marrocco [64] assessed the effects of scopolamine administration in the intraparietal cortex (IPC; 4 and $7 \mu \mathrm{g}$ in $1 \mu \mathrm{L}$ Ringer solution) in two rhesus monkeys trained on a Posner cued target detection task. After the highest scopolamine dose, performance accuracy was decreased and response latencies for peripheral targets were slowed, regardless of whether these targets were validly or invalidly cued. These data would suggest that muscarinic activity in the IPC plays a role in normal covert orienting of attention. A rat study by Barak and Weiner [66] demonstrated a dissociation between the role of muscarinic neurotransmission in the entorhinal cortex and basolateral amygdala, in modulating latent inhibition. Injections of scopolamine ( 1 and $10 \mu \mathrm{g} /$ side $)$ were found to disrupt latent inhibition when administered before preexposure or before both pre-exposure and conditioning, but not before conditioning alone. In contrast, scopolamine infused into the basolateral amygdala ( $10 \mu \mathrm{g} /$ side $)$ induced abnormally persistent latent inhibition when injected before conditioning or before both pre-exposure and conditioning, but not before pre-exposure alone. The authors concluded that muscarinic neurotransmission in the entorhinal cortex is implicated in the development of inattention to irrelevant stimuli. Muscarinic signaling in the basolateral aymgdala is important for re-attending to stimuli regarded as unimportant that have currently become behaviorally significant.

Another experiment by Herrero et al. [67] showed that in macaques performing a spatial attention task, attentional modulation (i.e., increase in firing rate after attending to the particular receptive field of a V1 neuron) was enhanced by iontophoretical application of $\mathrm{ACh}$, decreased by application of the muscarinic antagonist scopolamine, whereas the nicotinic antagonist mecamylamine had no effect. These findings are in line with a role of muscarinic rather than nicotinic receptors in attentional modulation of visual encoding.

\subsection{Central infusion of muscarinic agents: effects on other cognitive/behavioral functions}

There exist a great number of studies which have used central infusion of scopolamine in order to determine the role of certain brain regions in non-attentional types of behavior such as stimulus discrimination and short-term memory functions. A complete discussion of all these experiments is beyond the scope of this review; readers are referred to the review article by Klinkenberg and Blokland [3]. In short, studies that have used central administration of scopolamine do not provide a clear-cut picture of the 
role of the muscarinic system for each brain region. However, a rough differentiation can still be made; for instance, the cortical regions are involved in short-term memory functions [68-76], (conditional) discrimination [77-80], and conditioned taste aversion [81-83]. The amygdala and septohippocampal system appear necessary for anxiety-related behavior [84,85], and short-term memory [69,86-93]. The hippocampus has also been implicated in discrimination processes [86,94-96].

However, despite numerous articles claiming that central muscarinic blockade - especially in septum, hippocampus, amygala and cortical areas - disrupts short-term memory functions, there are some indications that impairments in attention might underlie these effects. For instance, scopolamine injections into septum [97,98], hippocampus [94-96,99-101], striatum [102], amygdala [103], nucleus accumbens [104] and several cortical areas (frontal cortex [76], prelimbic cortex [105], perirhinal cortex [106,107], insular cortex [81-83], and cingulate cortex [108]) have been shown to particularly disrupt the acquisition/encoding/learning phase rather than the retrieval/testing phase of memory paradigms. Since it is likely that attentional processes play a larger role in the former than the latter, at this point a central effect of scopolamine on attention instead of memory cannot be excluded.

Furthermore, several articles have suggested a role for muscarinic prefrontal neurotransmission in non-mnemonic functions. For instance, a study by Dunnett et al. [69] looked into the effects of muscarinic blockade by scopolamine in the PFC ( 4 injections of 4 or $12 \mu \mathrm{g}$ ) and dorsal hippocampus ( 3 injections of 4,12 or $35 \mu \mathrm{g}$ ) on delayed non-matching to position performance. Scopolamine administration ( $12 \mu \mathrm{g}$ for PFC vs. 12 and $35 \mu \mathrm{g}$ for hippocampus) disrupted delayed non-matching to position accuracy regardless of injection site. Interestingly, the nature of the deficits was different for the two brain regions; a delay-independent impairment was found after scopolamine injections into the PFC, whereas muscarinic antagonism in the hippocampus yielded a delay-dependent disturbance. These results were indicative of a role of the hippocampus but not the PFC in short-term memory processes; the PFC might be implicated in non-mnemonic (e.g., attentional) functions.

Using a delayed conditional discrimination task which precluded animals from using a mediating strategy, these findings were extended by Herremans et al. [78], who reported a delayindependent effect of intra-mPFC scopolamine administration. The authors concluded that the muscarinic system in the MPFC is involved in attention but not working memory processes. Another experiment used intra-PFC scopolamine infusion which disrupted responding in both matching to sample and non-matching to sample tasks [71]. However, since no delay procedures were used these data would not necessarily point towards a role of prefrontal muscarinic signaling in working memory functions. Hence, an underlying effect on attention cannot be excluded.

\subsection{Central infusion of nicotinic agents: effects on attention}

An experiment by Hahn et al. [109] attempted to determine the involvement of systemic and central nicotine injections $(1,2,4$, and $8 \mu \mathrm{g} /$ site, bilaterally) into the prelimbic area of the PFC and the dorsal hippocampus on performance in the 5-CSRTT. A subcutaneous dose of 0.1 or $0.2 \mathrm{mg} / \mathrm{kg}$ nicotine improved accuracy, reduced omissions and shortened response latency. Nicotine administered into the prelimbic area of the PFC improved response accuracy at a dose of $8 \mu \mathrm{g}$, bilaterally. There were no effects of nicotine infusion into the prelimbic PFC on parameters reflecting sensorimotor activation (i.e., rate and speed of responding). Intra-hippocampal nicotine injections had no effect on 5-CSRTT performance, which is in line with a role of this brain region in mnemonic instead of attentional functions [110]. Injections of the nicotinic antagonist neuronal bungarotoxin into the prelimbic area of the PFC yielded performance impairments in a matching to sample but not non-matching to sample task [71]. As the former paradigm was regarded as relatively more challenging, it was suggested that nicotinic signaling in PFC is mainly important for "effortful processing" (i.e., attention). In conclusion, these results point towards a role of the prelimbic PFC in the attention-enhancing rather than the psychostimulant effects of systemic nicotine treatment.

\subsection{Central infusion of nicotinic agents: effects on other cognitive/behavioral functions}

Central effects of nicotinic agonists and antagonists on nonattentional processes have been studied extensively in the last decades. We will give a short overview of the findings and discuss only the most influential experiments in more detail. First, when it comes to memory functions, nicotinic signaling in several brain areas appears to play an important role. The most important brain region for the mnemonic effects of systemically administered nicotine seems to be the hippocampus [110-116]. Using the 8-arm or 16 -arm radial maze, experiments have used intrahippocampal administration of either nicotine [112,113], the nonselective antagonist mecamylamine $[113,116]$, or selective nicotinic agents such as the $\alpha 7$ receptor antagonist methyllycaconitine (MLA) [110-112,114] and the $\alpha 4 \beta 2$ receptor antagonist dihydro- $\beta$ erythroidine $(\mathrm{DH} \beta \mathrm{E})[110,111,114,115]$ in order to determine the roles of specific nicotinic receptor subtypes in memory processes.

For instance, an elaborate study by Levin et al. [111] using the relatively more challenging 16 -arm radial maze has demonstrated that infusion of the $\alpha 7$ antagonist MLA ( $27 \mu \mathrm{g} /$ side) into the ventral hippocampus caused an increase in working but not reference memory errors. Injection of the $\alpha 4 \beta 2$ antagonist $\mathrm{DH} \beta \mathrm{E}$ $(6.75 \mu \mathrm{g} / \mathrm{side})$ into the same area gave rise to a disruption of both types of memory, although the effects on working memory performance were relatively more pronounced than those of reference memory. There were no confounding effects on response latency or on preconvulsive activity after drug treatment. Additive effects on working memory performance were seen after combined intrahippocampal administration of subthreshold doses of MLA (6.75 $\mu \mathrm{g} / \mathrm{side})$ and $\mathrm{DH} \beta \mathrm{E}(6.75 \mu \mathrm{g} / \mathrm{side})$. These results suggest that both the $\alpha 7$ and the $\alpha 4 \beta 2$ receptor subtypes in the ventral hippocampus play a role in working memory and that their effects might be mediated via similar downstream mechanisms.

However, the effects of nicotinic agents appear to be dependent on the part of the hippocampus which is targeted. Nott and Levin [110] administered MLA (6.75 $\mu \mathrm{g} /$ side), DHßE (1.69, 3.38, and $6.75 \mu \mathrm{g} /$ side) and combinations of both drugs in the dorsal hippocampus in rats trained on a 16-arm radial maze. Both MLA and $\mathrm{DH} \beta \mathrm{E}$ disrupted working memory, but not reference memory or response latency. However, after combination treatment which caused both $\alpha 7$ and $\alpha 4 \beta 2$ receptor blockade in the dorsal hippocampus, the working memory impairment was attenuated as compared to the single treatment conditions. These results implicate $\alpha 7$ and $\alpha 4 \beta 2$ receptor subtypes in dorsal hippocampus in spatial working memory but suggest that these two receptors work via different, downstream mechanisms which might have mutual antagonistic actions.

A study by Kim and Levin [113] extended the findings of Levin et al. [111] by assessing the effects of intrahippocampal administration of nicotine $(3,10$, and $30 \mu \mathrm{g} / \mu \mathrm{L})$, mecamylamine $(1.0,3.3$, and $10.0 \mu \mathrm{g} /$ side) and the muscarinic agonist pilocarpine ( 3 and $10 \mu \mathrm{g} / \mu \mathrm{L})$ and antagonist scopolamine $(1.0,3.3$, and $10.0 \mu \mathrm{g} /$ side $)$ in rats performing a 8 -arm radial maze. They reported that both nicotinic and muscarinic ACh receptors in ventral hippocampus play an important role in spatial working memory, as antagonism of either these receptors caused significant deficits in radial maze choice accuracy. Of note, infusions of nicotinic agents into nucleus 
accumbens did not affect spatial working memory performance in the radial maze. In addition to the hippocampus, nicotinic signaling in the basolateral amygdala (particularly the $\alpha 7$ and $\alpha 4 \beta 2$ receptor subtypes; [117]), the ventral tegmental area, substantia nigra [118] and mediodorsal thalamic nucleus (effects opposite to those reported in hippocampus and amygdala; [119]) seems also involved in working memory performance in the radial maze.

Secondly, cholinergic neurotransmission in septohippocampal brain regions is important for the control of anxiety [120-124]. However, the nature of effects of local administration of nicotinergic agents on anxiety is dependent on the nicotinic receptor subtype that is targeted, brain region and the type of behavioral task which is used, as different animal tests model different anxiety disorders. For instance, injections of nicotine $(0.1,4$, and $8 \mu \mathrm{g}$ for hippocampus, $4 \mu \mathrm{g}$ for septum) into dorsal hippocampus or lateral septum had an anxiogenic effect on behavior (i.e., it decreased social behavior) in the social interaction test, a model for generalized anxiety disorder [122]. Another study replicated and extended these findings by reporting that the effects of nicotine infusion $(1 \mu \mathrm{g}, 4.3 \mathrm{mM})$ into dorsal hippocampus on anxiety could be reversed by the $\alpha 7$ antagonist MLA ( $1.9 \mathrm{ng}, 4.3 \mu \mathrm{M})$ but not by the $\alpha 4 \beta 2$ antagonist $\mathrm{DH} \beta E(0.8 \mathrm{ng}, 4.3 \mu \mathrm{M})[120,124]$. This suggests that the anxiogenic effects of nicotine in the dorsal hippocampus are mediated by non- $\alpha 4 \beta 2$ nicotinic receptors. In contrast, infusion of nicotine ( $5 \mathrm{ng}$ ) into the dorsal raphé nucleus (DRN) increased social behavior in the social interaction test without affecting locomotor activity, indicative of an anxiolytic effect [125]. This effect was completely reversed by intra-raphé coadministration of $\mathrm{DH} \beta \mathrm{E}$ (100 ng) [125]. Thus, the anxiolytic effects of nicotine injection in the DRN are likely mediated by $\alpha 4 \beta 2$ nicotinic receptor subtypes.

In trial one of the elevated plus maze, the set-up is not elevated and is thought to model the escape component of panic disorder; during trial 2, the plus maze is elevated and models specific phobia $[122,123]$. Nicotine administration in hippocampus and lateral septum has distinct effects on behavior in each of these trials. In trial 1 , injections of nicotine $(1,4 \mu \mathrm{g})$ in lateral septum increase anxiety [126], whereas administration of nicotine ( $4 \mu \mathrm{g})$ in DRN has an anxiolytic effect [123]. Nicotinic signaling in the dorsal hippocampus does not play a role in controlling anxiety responses in trial 1 of the elevated plus maze [122]. In trial 2 an opposite pattern is seen; nicotine injection ( $4-8 \mu \mathrm{g})$ into the lateral septum is without effect, whereas intrahippocampal infusion of nicotine $(1 \mu \mathrm{g})$ decreases anxiety [123]. Lastly, very few experiments have assessed the effect of central administration of nicotinic compounds on locomotor activity [125,127]; infusions of the $\alpha 4 \beta 2$ antagonist DH $\beta E$ (100 ng) in DRN [125] or nicotine in ventral tegmental area of the forebrain [127] elevated locomotor activity. Nicotinic signaling in nucleus accumbens, striatum, dorsal hippocampus or motor thalamus does not seem to underlie the locomotor effects of systemically administered nicotine [127].

\subsection{Summary of pharmacological studies in rats}

Because of the limited number of studies using central infusion of muscarinic or nicotinic compounds to infer their effects on behavior in attentional tests, strong conclusions on the role of cholinergic signaling in discrete brain regions on attentional functions cannot be made. However, some indications can be given. Muscarinic receptors in frontal cortical regions (e.g., the mPFC and adlFC), the intra-parietal cortex, entorhinal cortex and basolateral amygdala seem important for attentional functions. Cortical regions are involved in short-term memory and sensory discrimination. Muscarinic signaling in septum, hippocampus and amygdala plays a role in anxiety and short-term memory; in addition, the hippocampus could be important for discrimination processes. The striatum and nucleus accumbens are also impli- cated in short-term memory. The effects of central infusion of scopolamine on mnemonic paradigms can often be characterized as disrupting acquisition and encoding rather than retrieval processes. Moreover, in delayed (non-)matching procedures, central muscarinic blockade often causes delay-independent performance impairments suggestive of actions on non-mnemonic functions. Thus, an underlying effect of central scopolamine administration on attention rather than memory can at this point not be excluded.

Only one study used central administration of nicotine to assess its involvement in 5-CSRTT performance. It was reported that nicotinic neurotransmission in prelimbic area of the PFC but not hippocampus is likely to play role in attention. The most important brain regions for the working memory effects of central nicotinic infusion are the hippocampus (in the ventral hippocampus possibly via interactions with the dopaminergic D2 system; [113]) and basolateral amygdala (particularly the $\alpha 7$ and the $\alpha 4 \beta 2$ nicotinic receptor subtypes), the ventral tegmental area, substantia nigra, and mediodorsal thalamic nucleus. Nicotinic receptors in the septum, hippocampus and DRN control anxiety responses (via interactions with the 5-HT system, particularly the $5-\mathrm{HT}_{1 \mathrm{a}}$ receptor subtypes; [122,125]); effects are dependent on the targeted nicotinic receptor subtype, brain region and the type of behavioral task which is used. In the DRN and ventral tegmental area, nicotinic neurotransmission plays a role in locomotor activity.

\section{Neuroimaging studies in humans}

As presented in the previous sections, cholinergic signaling in prefrontal and parietal areas appears to be most strongly implicated in attentional processes, at least in animals. Here we review human data and evaluate to what extent animal data can be translated to those found in human studies. Relatively many studies have been performed which looked into the role of ACh in human cognition. In studies with human participants, differentiations are normally made between various types of attention, such as selective, divided, or sustained attention, but also alerting, orienting, and executive functions. First we will give an overview of behavioral effects of nicotinic and muscarinic drugs, next we will look into imaging data in order to deduce which brain regions might underlie these cognitive-enhancing effects of cholinergic compounds. Finally, we will present data on the role of the cholinergic system in other types of cognition, mainly memory processing.

\subsection{Attention}

A recent meta-analysis showed that nicotine positively affects alerting and orienting response time [128], although Thiel et al. [129] and Thienel et al. [130] failed to find this alerting effect. Additionally, it has been found that nicotine predominantly improves aspects of attentional focusing and filtering, which relates to selective attention processes [129-131], rather than dividing attention over two or more stimuli simultaneously [131]. Muscarinic receptors seem to share this role in attention, playing a role in orienting and selective attention, but also executive function [132-134].

One way to examine the location where ACh may exert its effects on human attentional processes in the brain is by functional magnetic resonance imaging (fMRI). Here, hemodynamic changes in response to neuronal activity are assessed, which are a measure of activation or deactivation of the brain. A number of studies examined the effect of nicotine using nicotine patches or gums in smokers and non-smokers. Nicotine-induced deactivation was found in frontal, temporal, thalamic, and visual regions during a selective attention task $[131,135]$, but also in the cingulate cortex These brain areas overlap with the so-called default network of resting brain function, a network that is active at rest and deactivated during cognitive task performance. This would indicate that 
nicotine down-regulates resting brain function in response to taskrelated cues [136]. Interestingly, even though divided attention was not improved after nicotine treatment, nicotine did decrease brain activity in especially frontal areas during this task, suggesting that modulation of frontal regions reflects more global effects of nicotine [131]. Next to nicotine's effect in frontal regions, Thiel et al. $[129,137]$ also showed decreased (inferior) parietal activity during orienting to relevant stimuli after nicotine.

The findings of decreased neural activity after nicotine enhancement are in contrast with those of the nicotine antagonist mecamylamine [130]. Using an attentional network test, brain activation associated with orienting and executive function was down-regulated. Namely, mecamylamine decreased prefrontal, right precuneus, and left caudate activity during orienting and superior parietal areas and precuneus during executive function. This discrepancy is likely due to differences in test and stimulus design used [130]. Only one study assessed the effect of the muscarinic antagonist scopolamine on attention using fMRI [134]. Scopolamine reduced brain activity in left superior and left middle frontal brain regions during orienting attention in the attention network test.

Enhancement of cholinergic function using the cholinesterase inhibitor physostigmine that influences both nicotinic and muscarinic receptors has revealed the following effects. Physostigmine improved selective attention during an emotional task and augmented activity in the dorsolateral and medial prefrontal cortices, the orbitofrontal cortex, anterior cingulate, and temporal pole activity [138]. When comparing to the activity patterns which arose during performance of a working memory task, physostigmine increased the effect of attention in extrastriate occipital and prefrontal cortices and decreased activity in superior-medial parietal cortex [139]. Finally, especially under attention demanding stimulus encoding processes, physostigmine enhanced activity in the right fusiform cortex [140].

The nicotinic ACh $\alpha 4$ subunit gene CHRNA4 is a gene potentially playing a role in attentional function. Winterer et al. [141] assessed whether genetic variation within exon 5 of CHRNA4 is associated with selective attention. An association was indeed found with activation patterns in the anterior cingulate cortex and the left parietal cortex, suggesting that CHRNA4 may affect nicotine receptor sensitivity and attentional network function [141].

\subsection{Memory and other cognitive functions}

Human working memory function has frequently been related to the cholinergic system. It was found that smoking [142] or increasing nicotine using a gum or subcutaneous injection $[143,144]$ affects fronto-parietal networks during working memory performance using an $n$-back task. However, the results were mixed, with one study revealing increased activity in these areas [144] and another decreased activity [143]. Xu et al. [142] showed that the acute effects of nicotine may depend on recent prior smoking, with smoking after abstinence causing increases in fronto-parietal networks and smoking in a non-deprived state decreasing this activity in high stimulus load conditions. Blocking nicotinic receptors using mecamylamine decreased activity in the right medial frontal and superior frontal gyrus during an $n$-back task [145]. In the same study, the antimuscarinic drug scopolamine showed similar effects [145]. However, mecamylamine increased activity in the parahippocampal gyrus, an effect not shown after scopolamine.

Furey et al. [146] used a delayed matching to sample task, which is a paradigm that assesses working memory. Activation in visual cortical areas and inferior prefrontal cortex was increased after physostigmine infusion, whereas activity in dorsal anterior prefrontal regions was decreased during task performance [146]. The same task was used by Schon et al. [147] after scopolamine administration, but they correlated working memory related brain activity during the delay period with memory performance 20 min after encoding. Subsequent memory performance was predicted by sustained activity bilaterally in the perirhinal/entorhinal cortex, the right parahippocampal gyrus and the hippocampus. Scopolamine reduced this activity.

Some studies examined the role of the cholinergic system in shallow and/or deep stimulus encoding which was followed by a recognition task [140,148-150]. Chuah et al. [148] asked participants to classify words as living or non-living entities, a procedure of deep encoding, while recording brain activity with fMRI. They also assessed the effects of the acetylcholinesterase inhibitor donepezil on behavior and brain activation. After $45 \mathrm{~min}$, subsequent memory was assessed outside the scanner. Improved recognition after donepezil treatment correlated with increments in bilateral extrastriate and intraparietal regions during encoding. Other studies showed similar findings, demonstrating increased activation by physostigmine in fusiform cortex, parietal cortex and hippocampus $[140,149]$ and decreased activation in the fusiform area, hippocampus, and inferior prefrontal cortex after scopolamine [150]. Additionally, Kukolja et al. [149] found decreased amygdala activity during recognition of successfully encoded stimuli.

In two studies, participants merely memorized items in the encoding phase without the need for an overt response [151,152]. In those two experiments, brain activity was recorded during recognition. Scopolamine attenuated recognition-related activity in the fusiform cortex and increased activation in thalamic and intraparietal areas after impaired encoding of abstract shapes [152]. Recognizing words previously learned correlated with frontal, perirhinal, and cingulate cortex, especially for the presentation of new words, after treatment with scopolamine [151]. Thiel et al. [153] found that scopolamine decreased left fusiform activity during repetition of previously seen faces, indicating interference with acquisition processes.

\subsection{Summary of neuroimaging studies in humans}

Only one study specifically assessed the effect of muscarinic manipulations on brain activation related to attention. This paper showed a role for this receptor mainly in frontal cortical regions. Studies using physostigmine, which also partly affects muscarinic receptors, confirmed these findings. With regard to a role for nicotinic receptors, it was found that nicotinic manipulations predominantly affect (pre)frontal regions and parietal regions, although visual areas are also affected during performance of an attentional task. In this respect, it has been shown that both muscarinic and nicotinic receptors play a role in central visual processing [154], which is obviously necessary to perform any visual attentional task.

With regard to memory tests, the following results were found. The cholinergic system in fronto-parietal networks was shown to be relevant for performance during working memory paradigms such as the $n$-back task. Encoding of, for example, faces, words, or shapes was affected by cholinergic treatments, correlating with activation levels in frontal, hippocampal, parietal and fusiform structures. Recognition impairments after treatment with scopolamine were revealed by changes in activity patterns in a variety of structures, such as thalamic, intraparietal areas and several cortical regions (i.e., frontal, perirhinal, fusiform and cingulate cortex). The results of the human studies indicate that the cholinergic system is involved in both attention- and memory-related activity in frontal and parietal cortex, whereas structures such as the hippocampus and fusiform gyrus are more affected by cholinergic manipulations during memory processing. 


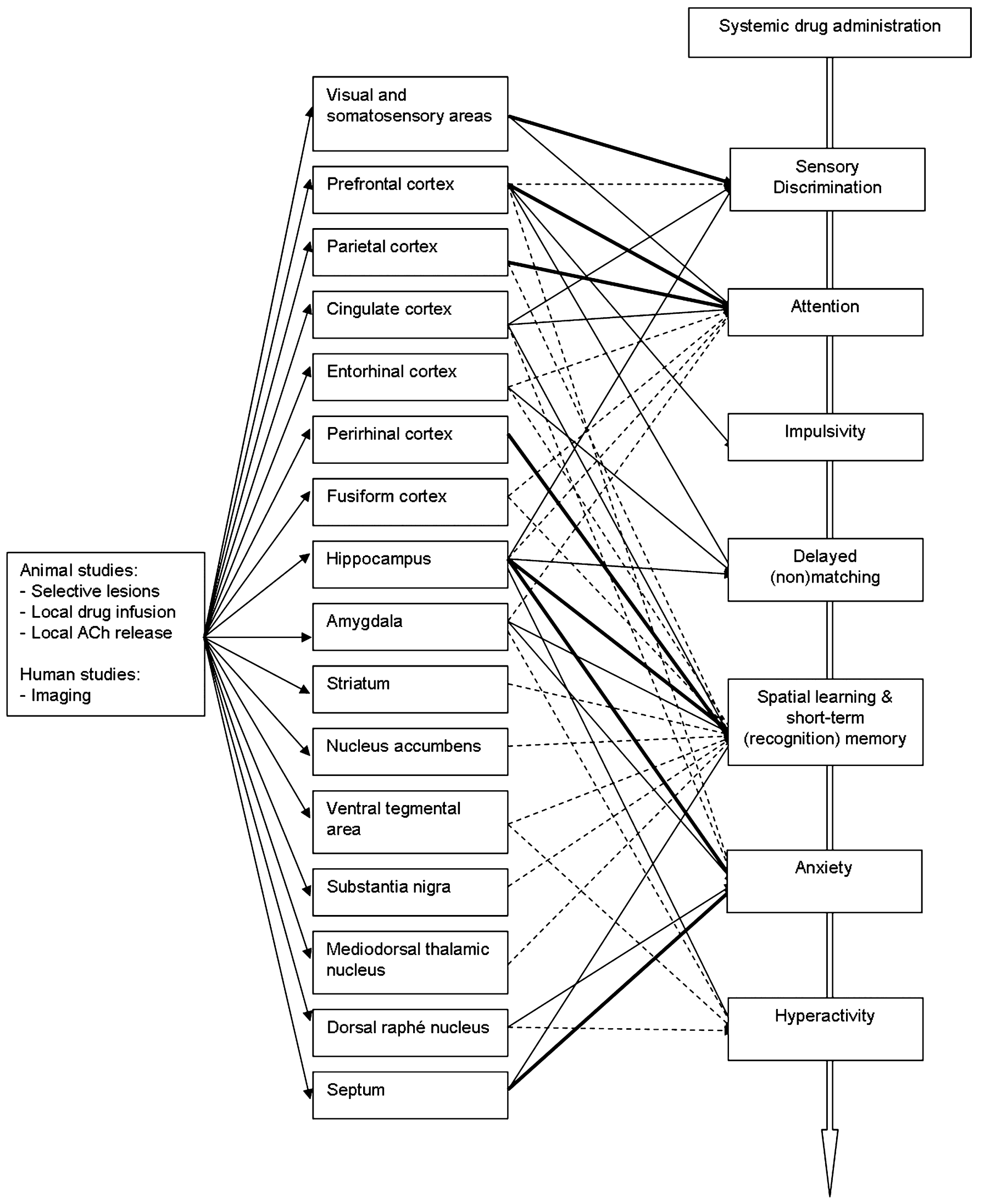

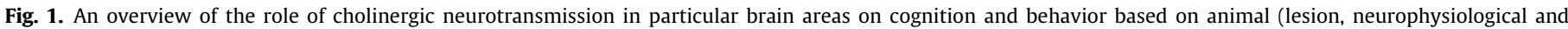

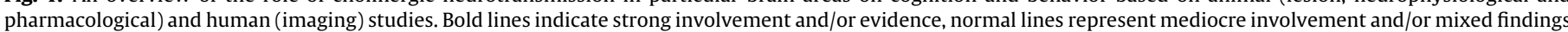

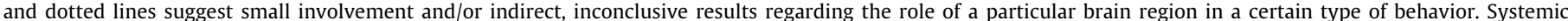
administration of cholinergic drugs is likely to diffusely affect all cognitive-behavioral functions which are mentioned in the figure. 


\section{Conclusions}

The current review article summarizes studies in animals and humans which have investigated the role of $\mathrm{ACh}$ in cognition. An attempt has been made to differentiate between brain regions involved in attentional processes versus those important for other cognitive functions. To this purpose, various experimental methods and interventions were used. Animal behavioral studies have injected the selective immunotoxin IgG-saporin to induce specific cholinergic lesions, employed neurophysiological techniques such as microdialysis, or have administered cholinergic compounds into discrete parts of the brain. Human studies that give some indication on the link between central cholinergic signaling and cognition are obviously confined to less invasive, imaging methods such as fMRI.

As is shown in Fig. 1, when it comes to different subdomains of cognition, strong, clear-cut dissociations between brain regions cannot be made on basis of the aforementioned data. Results are mixed, which could be partly due to differences in various experimental factors (for instance, between animal studies there could exist differences in rat strains, behavioral set-ups, etc.). Additionally, it is likely that complex behaviors and/or higher order cognitive processes such as attention are generated by the synchronized activity of a widespread neuronal network rather than by a single brain region which is clearly defined and whose sole function is just one particular cognitive domain [155].

Nevertheless, the brain areas that are deemed most important for intact attentional processing in both animals and humans appear to be the (pre)frontal, parietal and somatosensory (especially visual) regions. We would like to propose that in these regions, ACh plays a vital role in the top-down control of attention. In contrast, cholinergic signaling in the septohippocampal system is likely to be involved in memory processes. Furthermore, it is likely that the role of ACh is different per brain region and between nicotinic versus muscarinic receptor subtypes. We would like to suggest that within the short-term memory network, hippocampal ACh is important for acquisition of new information; in the amygdala ACh plays a role in anxiety, and in the perirhinal cortex ACh is involved in (object) recognition processes. ACh regulates top-down control of attention in the parietal cortex by influencing orienting responses, whereas in somatosensory areas such as visual cortex, cholinergic signaling improves the signal-to-noise ratio and thus enhances stimulus discrimination.

Future studies on the role of ACh in attention should mainly focus on the (pre)frontal, parietal and somatosensory cortices. In animal research, new microdialysis techniques which allow the measurement of ACh efflux on different timescales (i.e., tonic release on the scale of minutes and phasic release on the scale of seconds) should allow for a more in-depth view of the influence of cholinergic signaling on attentional functions. In addition, there exists a great lack in animal experiments that use central infusion of nicotinic and muscarinic compounds to investigate the differential role of specific cholinergic receptor subtypes and brain regions involved in attention vs. other cognitive processes. Ultimately we might be able to extrapolate these findings to neuropsychiatric populations in which attention is disrupted, such as Alzheimer's disease, attention-deficit disorder and schizophrenia.

\section{Conflict of interest}

The authors declare that, except for income received from their primary employer, no financial support or compensation has been received from any individual or corporate entity over the past three years for research or professional service and there are no personal financial holdings that could be perceived as constituting a potential conflict of interest.

\section{References}

[1] Bartus RT, Dean RL, Beer B, Lippa AS. The cholinergic hypothesis of geriatric memory dysfunction. Science 1982;217:408-17.

[2] Bartus RT, Dean RL, Pontecorvo MJ, Flicker C. The cholinergic hypothesis: a historical overview, current perspective, and future directions. Ann N Y Acad Sci 1985;444:332-58.

[3] Klinkenberg I, Blokland A. The validity of scopolamine as a pharmacological model for cognitive impairment: a review of animal behavioral studies. Neurosci Biobehav Rev 2010;34:1307-50.

[4] Gauthier S, Scheltens P. Can we do better in developing new drugs for Alzheimer's disease? Alzheimer's Dement 2009;5:489-91.

[5] Lockhart IA, Mitchell SA, Kelly S. Safety and tolerability of donepezil, rivastigmine and galantamine for patients with Alzheimer's disease: systematic review of the 'real-world' evidence. Dement Geriatr Cogn Disord 2009;28:389-403.

[6] Cincotta SL, Yorek MS, Moschak TM, Lewis SR, Rodefer JS. Selective nicotinic acetylcholine receptor agonists: potential therapies for neuropsychiatric disorders with cognitive dysfunction. Curr Opin Investig Drugs 2008;9:4756.

[7] Leiser SC, Bowlby MR, Comery TA, Dunlop J. A cog in cognition: how the alpha7 nicotinic acetylcholine receptor is geared towards improving cognitive deficits. Pharmacol Ther 2009;122:302-11.

[8] Feuerbach D, Lingenhoehl K, Olpe HR, Vassout A, Gentsch C, Chaperon F, et al. The selective nicotinic acetylcholine receptor alpha7 agonist JN403 is active in animal models of cognition, sensory gating, epilepsy and pain. Neuropharmacology 2009;56:254-63.

[9] JakubikJ, Michal P, Machova E, Dolezal V. Importance and prospects for design of selective muscarinic agonists. Physiol Res 2008;57(Suppl. 3):S39-47.

[10] Bradley SR, Lameh J, Ohrmund L, Son T, Bajpai A, Nguyen D, et al. AC260584, an orally bioavailable $\mathrm{M}(1)$ muscarinic receptor allosteric agonist, improves cognitive performance in an animal model. Neuropharmacology 2010;58:365-73.

[11] Blokland A. Acetylcholine: a neurotransmitter for learning and memory? Brain Res Rev 1995;21:285-300.

[12] Muir JL. Acetylcholine, aging, and Alzheimer's disease. Pharmacol Biochem Behav 1997;56:687-96.

[13] Rasmusson DD. The role of acetylcholine in cortical synaptic plasticity. Behav Brain Res 2000;115:205-18.

[14] Sarter M, Bruno JP. Cognitive functions of cortical acetylcholine: toward a unifying hypothesis. Brain Res Rev 1997:23:28-46.

[15] McGaughy J, Everitt BJ, Robbins TW, Sarter M. The role of cortical cholinergic afferent projections in cognition: impact of new selective immunotoxins. Behav Brain Res 2000;115:251-63.

[16] Parikh V, Kozak R, Martinez V, Sarter M. Prefrontal acetylcholine release controls cue detection on multiple timescales. Neuron 2007;56:141-54.

[17] Goard M, Dan Y. Basal forebrain activation enhances cortical coding of natural scenes. Nat Neurosci 2009;12:1440-7.

[18] Parasuraman R, Greenwood PM, Kumar R, Fossella J. Beyond heritability: neurotransmitter genes differentially modulate visuospatial attention and working memory. Psychol Sci 2005;16:200-7.

[19] Wiley RG. Neural lesioning with ribosome-inactivating proteins: suicide transport and immunolesioning. Trends Neurosci 1992;15:285-90.

[20] Torres EM, Perry TA, Blokland A, Wilkinson LS, Wiley RG, Lappi DA, et al. Behavioural, histochemical and biochemical consequences of selective immunolesions in discrete regions of the basal forebrain cholinergic system. Neuroscience 1994;63:95-122.

[21] Baxter M, Gallagher M. Intact spatial learning in both young and aged rats following selective removal of hippocampal cholinergic input. Behav Neurosci 1996;110:460-7.

[22] McMahan RW, Sobel TJ, Baxter MG. Selective immunolesions of hippocampal cholinergic input fail to impair spatial working memory. Hippocampus 1997; 7:130-6.

[23] Waite JJ, Chen AD, Wardlow ML, Wiley RG, Lappi DA, Thal LJ. 192 immunoglobulin G-saporin produces graded behavioral and biochemical changes accompanying the loss of cholinergic neurons of the basal forebrain and cerebellar Purkinje cells. Neuroscience 1995;65:463-76.

[24] Harati H, Barbelivien A, Cosquer B, Majchrzak M, Cassel JC. Selective cholinergic lesions in the rat nucleus basalis magnocellularis with limited damage in the medial septum specifically alter attention performance in the five-choice serial reaction time task. Neuroscience 2008;153:72-83.

[25] Fletcher BR, Baxter MG, Guzowski JF, Shapiro ML, Rapp PR. Selective cholinergic depletion of the hippocampus spares both behaviorally induced Arc transcription and spatial learning and memory. Hippocampus 2007; 17:227-34.

[26] Perry T, Hodges H, Gray JA. Behavioural, histological and immunocytochemical consequences following 192 IgG-saporin immunolesions of the basal forebrain cholinergic system. Brain Res Bull 2001:29-48.

[27] van der Staay FJ, Bouger P, Lehmann O, Lazarus C, Cosquer B, Koenig J, et al. Long-term effects of immunotoxic cholinergic lesions in the septum on acquisition of the cone-field task and noncognitive measures in rats. Hippocampus 2006; 16:1061-79.

[28] Fitz NF, Gibbs RB, Johnson DA. Selective lesion of septal cholinergic neurons in rats impairs acquisition of a delayed matching to position T-maze task by delaying the shift from a response to a place strategy. Brain Res Bull 2008;77:356-60. 
[29] Lehmann O, Grottick AJ, Cassel JC, Higgins GA. A double dissociation between serial reaction time and radial maze performance in rats subjected to $192 \mathrm{IgG}-$ saporin lesions of the nucleus basalis and/or the septal region. Eur J Neurosci 2003;18:651-66.

[30] Fitz NF, Gibbs RB, Johnson DA. Aversive stimulus attenuates impairment of acquisition in a delayed match to position T-maze task caused by a selective lesion of septo-hippocampal cholinergic projections. Brain Res Bull 2006;69:660-5.

[31] Pioro EP, Cuello AC. Purkinje cells of adult rat cerebellum express nerve growth factor receptor immunoreactivity: light microscopic observations. Brain Res 1988;455:182-6.

[32] Moreau PH, Cosquer B, Jeltsch H, Cassel JC, Mathis C. Neuroanatomical and behavioral effects of a novel version of the cholinergic immunotoxin mu p75saporin in mice. Hippocampus 2008:610-22.

[33] Nag N, Baxter MG, Berger-Sweeney JE. Efficacy of a murine-p75-saporin immunotoxin for selective lesions of basal forebrain cholinergic neurons in mice. Neurosci Lett 2009;452:247-51.

[34] Baxter MG, Holland PC, Gallagher M. Disruption of decrements in conditioned stimulus processing by selective removal of hippocampal cholinergic input. J Neurosci 1997; 17:5230-6.

[35] Lecourtier L, de Vasconcelos AP, Leroux E, Cosquer B, Geiger K, Lithfous S, et al. Septohippocampal pathways contribute to system consolidation of a spatial memory: sequential implication of gabaergic and cholinergic neurons. Hippocampus (2010), doi:10.1002/hipo.20837.

[36] Newman LA, McGaughy J. Cholinergic deafferentation of prefrontal cortex increases sensitivity to cross-modal distractors during a sustained attention task. J Neurosci 2008:28:2642-50.

[37] Dalley JW, Theobald DE, Bouger P, Chudasama Y, Cardinal RN, Robbins TW. Cortical cholinergic function and deficits in visual attentional performance in rats following 192 IgG-saporin-induced lesions of the medial prefrontal cortex. Cereb Cortex 2004:14:922-32.

[38] Bucci DJ, Holland PC, Gallagher M. Removal of cholinergic input to rat posterior parietal cortex disrupts incremental processing of conditioned stimuli. J Neurosci 1998; $18: 8038-46$

[39] Winters BD, Robbins TW, Everitt BJ. Selective cholinergic denervation of the cingulate cortex impairs the acquisition and performance of a conditional visual discrimination in rats. Eur J Neurosci 2004;19:490-6.

[40] McGaughy J, Koene RA, Eichenbaum H, Hasselmo ME. Cholinergic deafferentation of the entorhinal cortex in rats impairs encoding of novel but not familiar stimuli in a delayed nonmatch-to-sample task. J Neurosci 2005;25:10273-81.

[41] Sarter M, Bruno JP, Givens B, Moore H, McGaughy J, McMahon K. Neuronal mechanisms mediating drug-induced cognition enhancement: $\operatorname{cog}$ nitive activity as a necessary intervening variable. Cognitive Brain Res 1996;3:329-43.

[42] Moore H, Sarter M, Bruno JP. Age-dependent modulation of in vivo cortical acetylcholine release by benzodiazepine receptor ligands. Brain Res 1992;596:17-29.

[43] Inglis FM, Day JC, Fibinger HC. Enhanced acetylcholine release in hippocampus and cortex during the anticipation and consumption of a palatable meal. Neuroscience 1994;62:1049-56.

[44] Day J, Damsma G, Fibiger HC. Cholinergic activity in the rat hippocampus, cortex and striatum correlates with locomotor activity: an in vivo microdialysis study. Pharmacol Biochem Behav 1991;38:723-9.

[45] Dudar JD, Wishaw IQ, Szerb JC. Release of acetylcholine from the hippocampus of freely moving rats during sensory stimulation and running. Neuropsychopharmacology 1979;18:673-8.

[46] Nilsson OG, Kalen P, Rosengren E, Björklund A. Acetylcholine release in the rat hippocampus as studied by microdialysis is dependent on axonal impulse flow and increases during behavioural activation. Neuroscience 1990;36:325-38.

[47] Himmelheber AM, Sarter M, Bruno JP. Operant performance and cortical acetylcholine release: role of response rate, reward density, and noncontingent stimuli. Cognitive Brain Res 1997;6:23-6.

[48] Parikh V, Sarter M. Cholinergic mediation of attention: contributions of phasic and tonic increases in prefrontal cholinergic activity. Ann N Y Acad Sci 2008;1129:225-35.

[49] Sarter M, Parikh V, Howe WM. Phasic acetylcholine release and the volume transmission hypothesis: time to move on. Nat Rev Neurosci 2009;10:38390.

[50] Passetti F, Dalley JW, O'Connell MT, Everitt BJ, Robbins TW. Increased acetylcholine release in the rat medial prefrontal cortex during performance of a visual attentional task. Eur J Neurosci 2000;12:3051-8.

[51] Dalley JW, McGaughy J, O'Connell MT, Cardinal RN, Levita L, Robbins TW. Distinct changes in cortical acetylcholine and noradrenaline efflux during contingent and noncontingent performance of a visual attentional task. J Neurosci 2001;21:4908-14.

[52] Acquas E, Wilson C, Fibiger HC. Conditioned and unconditioned stimuli increase frontal cortical and hippocampal acetylcholine release: effects of novelty, habituation, and fear. J Neurosci 1996;16:3089-96.

[53] Nail-Boucherie K, Dourmap N, Jaffard R, Costentin J. Contextual fear conditioning is associated with an increase of acetylcholine release in the hippocampus of rat. Cognitive Brain Res 2000;9:193-7.

[54] Hata T, Kumai K, Okaichi H. Hippocampal acetylcholine efflux increases during negative patterning and elemental discrimination in rats. Neurosci Lett 2007; $418: 127-32$.
[55] Thiel CM, Huston JP, Schwarting RKW. Cholinergic activation in frontal cortex and nucleus accumbens related to basic behavioral manipulations: handling, and the role of post-handling experience. Brain Res 1998;812:12132

[56] Inglis FM, Fibinger HC. İncreases in hippocampal and frontal cortical acetylcholine release associated with presentation of sensory stimuli. Neuroscience 1995:66:81-6.

[57] Giovannini MG, Rakovska A, Benton RS, Pazzagli M, Bianchi L, Pepeu G. Effects of novelty and habituation on acetylcholine, GABA, and glutamate release from the frontal cortex and hippocampus of freely moving rats. Neuroscience 2001;106:43-53.

[58] Himmelheber AM, Sarter M, Bruno JP. Increases in cortical acetylcholine release during sustained attention performance in rats. Cognitive Brain Res 2000;9:313-25.

[59] Himmelheber AM, Sarter M, Bruno JP. The effects of manipulations of attentional demand on cortical acetylcholine release. Cognitive Brain Res 2001;12:353-70.

[60] Arnold HM, Burk JA, Hodgson EM, Sarter M, Bruno JP. Differential cortical acetylcholine release in rats performing a sustained attention task versus behavioral control tasks that do not explicitly task attention. Neuroscience 2002:114:451-60.

[61] Fournier GN, Semba K, Rasmusson DD. Modality- and region-specific acetylcholine release in the rat neocortex. Neuroscience 2004;126:257-62.

[62] Kozak R, Bruno JP, Sarter M. Augmented prefrontal acetylcholine release during challenged attentional performance. Cereb Cortex 2006;16:9-17.

[63] Hasselmo ME. The role of acetylcholine in learning and memory. Curr Opin Neurobiol 2006;16:710-5

[64] Davidson MC, Marrocco RT. Local infusion of scopolamine into intraparietal cortex slows covert orienting in rhesus monkeys. J Neurophysio 2000;83:1536-49.

[65] Robbins TW, Granon S, Muir JL, Durantou F, Harrison A, Everitt BJ. Neural systems underlying arousal and attention: implications for drug abuse. Ann N Y Acad Sci 1998;846:222-37.

[66] Barak S, Weiner I. Differential role of muscarinic transmission within the entorhinal cortex and basolateral amygdala in the processing of irrelevant stimuli. Neuropsychopharmacology 2010;35:1073-82.

[67] Herrerro JL, Roberts MJ, Delicato LS, Gieselmann MA, Dayan P, Thiele A. Acetylcholine contributes through muscarinic receptors to attentional modulation in V1. Nature 2008:454:1110-4.

[68] Broersen LM, Heinsbroek RPW, de Bruin JPC, Joosten RNJ, van Hest A, Olivier B. Effects of local application of dopaminergic drugs into the dorsal part of the medial prefrontal cortex of rats in a delayed matching to position task: comparison with local cholinergic blockade. Brain Res 1994;645:113-22.

[69] Dunnett SB, Wareham AT, Torres EM. Cholinergic blockade in prefrontal cortex and hippocampus disrupts short-term memory in rats. Neuroreport 1990; $1: 61-4$.

[70] Herremans AHJ, Hijzen TH, Welborn PFE, Olivier B, Slangen JL. Effects of infusion of cholinergic drugs into the prefrontal cortex area on delayed matching to position performance in the rat. Brain Res 1996;711:102-11.

[71] Granon S, Poucet B, Thinus-Blanc C, Changeux J-P, Vidal C. Nicotinic and muscarinic receptors in the rat prefrontal cortex: differential roles in working memory, response selection and effortful processing. Psychopharmacology (Berl) 1995;119:139-44.

[72] Wall PM, Flinn J, Messier C. Infralimbic muscarinic M1 receptors modulate anxiety-like behaviour and spontaneous working memory in mice. Psychopharmacology (Berl) 2001:155:58-68.

[73] Winters BD, Saksida LM, Bussey TJ. Paradoxical facilitation of object recognition memory after infusion of scopolamine into perirhinal cortex: implications for cholinergic system function. J Neurosci 2006;26:9520-9.

[74] Abe H, Ishida Y, Iwasaki T. Perirhinal N-methyl-D-aspartate and muscarinic systems participate in object recognition in rats. Neurosci Lett 2004;356:191-4

[75] Warburton EC, Koder T, Kwangwook C, Massey PV, Duguid G, Barker GRI, et al. Cholinergic neurotransmission is essential for perirhinal cortical plasticity and recognition memory. Neuron 2003;38:987-96

[76] Santucci AC, Shaw C. Peripheral 8-OH-DPAT and scopolamine infused into the frontal cortex produce passive avoidance retention impairments in rats. Neurobiol Learn Mem 2003;79:136-41

[77] Wilson DA. Scopolamine enhances generalization between odor representations in rat olfactory cortex. Learn Mem 2001;8:279-85

[78] Herremans AHJ, Hijzen TH, Olivier B. Effects of cholinergic drug infusions into the dorsal part of the medial prefrontal cortex on delayed conditional discrimination peformance in the rat. Behav Brain Res 1997;84:291-9.

[79] Broersen LM, Heinsbroek RPW, de Bruin JPC, Uylings HBM, Olivier B. The role of the medial prefrontal cortex of rats in short-term memory functioning: further support for involvement of cholinergic, rather than dopaminergic mechanisms. Brain Res 1995;674:221-9.

[80] Ragozzino ME, Kesner RP. The effects of muscarinic cholinergic receptor blockade in the rat anterior cingulate and prelimbic/infralimbic cortices on spatial working memory. Neurobiol Learn Mem 1998;69:241-57.

[81] Gutiérrez R, Rodriguez-Ortiz CJ. De La Cruz V, Núnez-Jaramillo L, BermudezRattoni F. Cholinergic dependence of taste memory formation: evidence of two distinct processes. Neurobiol Learn Mem 2003;80:323-31.

[82] Ramírez-Lugo L, Miranda MI, Escobar ML, Espinosa E, Bermúdez-Rattoni F. The role of cortical cholinergic pre- and post-synaptic receptors in taste memory formation. Neurobiol Learn Mem 2003;79:184-93. 
[83] Naor C, Dudai Y. Transient impairment of cholinergic function in the rat insular cortex disrupts the encoding of taste in conditioned taste aversion. Behav Brain Res 1996;79:61-7.

[84] Smythe JW, Bhatnagar S, Murphy D, Timothy C, Costall B. The effects of intrahippocampal scopolamine infusions on anxiety in rats as measured by the black-white box test. Brain Res Bull 1998;45:89-93.

[85] File SE, Gonzalez LE, Andrews N. Endogenous acetylcholine in the dorsa hippocampus reduces anxiety through actions on nicotinic and muscarinic1 receptors. Behav Neurosci 1998;112:352-9.

[86] Brito GNO, Davis BJ, Stopp LC, Stanton ME. Memory and the septohippocampal cholinergic system in the rat. Psychopharmacology (Berl) 1983;81:315-20.

[87] Mishima K, Iwasaki K, Tsukikawa H, Matsumoto Y, Egashira N, Abe K, et al. The scopolamine-induced impairment of spatial cognition parallels the acetylcholine release in the ventral hippocampus in rats. Jpn J Pharmacol 2000;84:163-73.

[88] Herrera-Morales W, Mar I, Serrano B, Bermúdez-Rattoni F. Activation of hippocampal postsynaptic muscarinic receptors is involved in long-term spatial memory formation. Eur J Neurosci 2007;25:1581-8.

[89] Markowska AL, Olton DS, Givens B. Cholinergic manipulations in the medial septal area: age-related effects on working memory and hippocampal electrophysiology. J Neurosci 1995;15:2063-73.

[90] Givens B, Olton DS. Bidirectional modulation of scopolamine-induced working memory impairments by muscarinic activation of the medial septal area. Neurobiol Learn Mem 1995;63:269-76.

[91] Ingles JL, Beninger RJ, Jhamandas K, Boegman RJ. Scopolamine injected into the rat amygdala impairs working memory in the double Y-maze. Brain Res Bull 1993;32:339-44.

[92] Ohno M, Yamamoto T, Watanabe S. Amygdaloid NMDA and muscarinic receptors involved in working memory performance of rats. Physiol Behav 1993;54:993-7.

[93] McIntyre CK, Ragozzino ME, Gold PE. Intra-amygdala infusions of scopolamine impair performance on a conditioned place preference task but not a spatial radial maze task. Behav Brain Res 1998;95:219-26.

[94] Carli M, Luschi R, Samanin R. (S)-WAY 100135, a 5-HT 1 A receptor antagonist, prevents the impairment of spatial learning caused by intrahippocampal scopolamine. Eur J Pharmacol 1995;283:133-9.

[95] Carli M, Luschi R, Samanin R. Dose-related impairment of spatial learning by intrahippocampal scopolamine: antagonism by odansetron, a 5- $\mathrm{HT}_{3}$ receptor antagonist. Behav Brain Res 1997;82:185-94.

[96] Carli M, Balducci C, Millan MJ, Bonalumi P, Samanin R. S 15535, a benzodioxopiperazine acting as presynaptic agonist and postsynaptic 5-HT1A receptor antagonist, prevents the impairment of spatial learning caused by intrahippocampal scopolamine. Br J Pharmacol 1999;128:1207-14.

[97] Hamilton LW, Grossman SP. Behavioral changes following disruption of central cholinergic pathways. J Comp Physiol Psychol 1969;69:76-82.

[98] Elvander E, Schött PA, Sandin J, Bjelke B, Kehr J, Yoshitake T, et al. Intraseptal muscarinic ligands and galanin: influence on hippocampal acetylcholine and cognition. Neuroscience 2004;126:541-57.

[99] Bermúdez-Rattoni F, Coburn KL, Fernandez J, Chavez AF, Garcia J. Potentiation of odor by taste and odor aversions in rats are regulated by cholinergic activity of dorsal hippocampus. Pharmacol Biochem Behav 1987;26:553-9.

[100] Blokland A, Honig W, Raaijmakers WGM. Effects of intra-hippocampal scopolamine injections in a repeated spatial acquisition task in the rat. Psychopharmacology (Berl) 1992;109:373-6.

[101] Rogers JL, Kesner RP. Cholinergic modulation of the hippocampus during encoding and retrieval of tone/shock-induced fear conditioning. Learn Mem 2004; 11:102-7.

[102] Bermúdez-Rattoni F, Mujica Gonzalez M, Prado Alcala RA. Is cholinergic activity of the striatum involved in the acquisition of positively-motivated behaviors? Pharmacol Biochem Behav 1986;24:715-9.

[103] Carballo-Márquez A, Vale-Martínez A, Guillazo-Blanch G, Martí-Nicolovius M. Muscarinic transmission in the basolateral amygdala is necessary for the acquisition of socially transmitted food preferences in rats. Neurobiol Learn Mem 2009;91:98-101.

[104] Pratt WE, Kelley AE. Nucleus accumbens acetylcholine regulates appetitive learning and motivation for food via activation of muscarinic receptors. Behav Neurosci 2004;118:730-9.

[105] Boix-Trelis N, Vale-Martínez A, Guillazo-Blanch G, Martí-Nicolovius M. Muscarinic cholinergic receptor blockade in the rat prelimbic cortex impairs the social transmission of food preference. Neurobiol Learn Mem 2007;87:659-68

[106] Gutiérrez R, De la Cruz V, Rodriguez-Ortiz CJ, Bermudez-Rattoni F. Perirhinal cortex muscarinic receptor blockade impairs taste recognition memory formation. Learn Mem 2004;11:95-101.

[107] Winters BD, Bartko SJ, Saksida LM, Bussey TJ. Scopolamine infused into perirhinal cortex improves object recognition memory by blocking the acquisition of interfering object information. Learn Mem 2007;14:590-6.

[108] Riekkinen Jr P, Kuitunen J, Riekkinen M. Effects of scopolamine infusions into the anterior and posterior cingulate on passive avoidance and water maze navigation. Brain Res 1995;685:46-54.

[109] Hahn B, Shoaib M, Stolerman IP. Involvement of the prefrontal cortex but not the dorsal hippocampus in the attention-enhancing effects of nicotine in rats. Psychopharmacology (Berl) 2003;168:271-9.

[110] Nott A, Levin ED. Dorsal hippocampal $\alpha 7$ and $\alpha 4 \beta 2$ nicotinic receptors and memory. Brain Res 2006;1081:72-8.
[111] Levin ED, Bradley A, Addy N, Sigurani N. Hippocampal $\alpha 7$ and $\alpha 4 \beta 2$ nicotinic receptors and working memory. Neuroscience 2002;109:757-65.

[112] Bettany JH, Levin ED. Ventral hippocampal $\alpha 7$ nicotinic receptor blockade and chronic nicotine effects on memory performance in the radial-arm maze. Pharmacol Biochem Behav 2001;70:467-74.

[113] Kim JS, Levin ED. Nicotinic, muscarinic and dopaminergic actions in the ventral hippocampus and the nucleus accumbens: effects on spatial working memory in rats. Brain Res 1996;725:231-40.

[114] Felix R, Levin ED. Nicotinic antagonist administration into the ventral hippocampus and spatial working memory in rats. Neuroscience 1997;81:1009-77.

[115] Bancroft A, Levin ED. Ventral hippocampal $\alpha 4 \beta 2$ nicotinic receptors and chronic nicotine effects on memory. Neuropharmacology 2000;39:2770-8.

[116] Ohno M, Yamamoto T, Shigenori W. Blockade of hippocampal nicotinic receptors impairs working but not reference memory in rats. Pharmacol Biochem Behav 1993;45:89-93.

[117] Addy NA, Nakijama A, Levin ED. Nicotinic mechanisms of memory: effects of acute local DHßE and MLA infusions in the basolateral amygdala. Cognitive Brain Res 2003;16:51-7.

[118] Levin ED, Briggs SJ, Christopher NC, Auman JT. Working memory performance and cholinergic effects in the ventral tegmental area and substantia nigra. Brain Res 1994;657:165-70.

[119] Cannady R, Weir R, Wee B, Gotschlich E, Kolia N, Lau E, et al. Nicotinic antagonist effects in the mediodorsal thalamic nucleus: regional heterogeneity of nicotinic receptor involvement in cognitive function. Biochem Pharmacol 2009;78:788-94

[120] Tucci SA, Genn RF, File SE. Methyllycaconitine (MLA) blocks the nicotine evoked anxiongenic effect and 5-HT release in the dorsal hippocampus: possible role of $\alpha 7$ receptors. Neuropharmacology 2003;44:367-73.

[121] Vago DR, Kesner RP. Cholinergic modulation of pavlovian fear conditioning in rats: differential effects of intrahippocampal infusion of mecamylamine and methyllycaconitine. Neurobiol Learn Mem 2007;87:441-9.

[122] Cheeta S, Kenny PJ, File SE. Hippocampal and septal injections of nicotine and 8-OH-DPAT distinguish among different animal tests of anxiety. Prog Neuro-Psychoph 2000;24:1053-67.

[123] File SE, Cheeta S, Kenny PJ. Neurobiological mechanisms by which nicotine mediates different types of anxiety. Eur J Pharmacol 2000;393:231-6.

[124] File SE, Kenny PJ, Cheeta S. The role of the dorsal hippocampal serotonergic and cholinergic systems in the modulation of anxiety. Pharmacol Biochem Behav 2000;66:65-72.

[125] Cheeta S, Tucci S, File SE. Antagonism of the anxiolytic effect of nicotine in the dorsal raphé nucleus by di-hyrdo- $\beta$-erythroidine. Pharmacol Biochem Behav 2001;70:491-6.

[126] Ouagazzal AM, Kenny PJ, File SE. Stimulation of nicotinic receptors in the lateral septal nucleus increases anxiety. Eur J Neurosci 1999;11:3957-62.

[127] Reavill C, Stolerman IP. Locomotor activity in rats after administration of nicotinic agonists intracerebrally. Br J Pharmacol 1990;99:273-8.

[128] Heishman SJ, Kleykamp BA, Singleton EG. Meta-analysis of the acute effects of nicotine and smoking on human performance. Psychopharmacology (Berl) 2010;210:453-69.

[129] Thiel CM, Zilles K, Fink GR. Nicotine modulates reorienting of visuospatial attention and neural activity in human parietal cortex. Neuropsychopharmacology 2005;30:810-20.

[130] Thienel R, Voss B, Kellermann T, Reske M, Halfter S, Sheldrick AJ, et al. Nicotinic antagonist effects on functional attention networks. Int J Neuropsychopharmacol 2009; $12: 1295-305$.

[131] Hahn B, Ross TJ, Wolkenberg FA, Shakleya DM, Huestis MA, Stein EA. Performance effects of nicotine during selective attention, divided attention, and simple stimulus detection: an fMRI study. Cereb Cortex 2009;19:1990-2000.

[132] Fredrickson A, Snyder PJ, Cromer J, Thomas E, Lewis M, Maruff P. The use of effect sizes to characterize the nature of cognitive change in psychopharmacological studies: an example with scopolamine. Hum Psychopharmacol 2008;23:425-36.

[133] Furey ML, Pietrini P, Haxby JV, Drevets WC. Selective effects of cholinergic modulation on task performance during selective attention. Neuropsychopharmacology 2008;33:913-23.

[134] Thienel R, Kellermann T, Schall U, Voss B, Reske M, Halfter S, et al. Muscarinic antagonist effects on executive control of attention. Int J Neuropsychopharmacol 2009;12:1307-17.

[135] Lawrence NS, Ross TJ, Stein EA. Cognitive mechanisms of nicotine on visual attention. Neuron 2002;36:539-48.

[136] Hahn B, Ross TJ, Yang Y, Kim I, Huestis MA, Stein EA. Nicotine enhances visuospatial attention by deactivating areas of the resting brain default network. J Neurosci 2007;27:3477-89.

[137] Thiel CM, Fink GR. Effects of the cholinergic agonist nicotine on reorienting of visual spatial attention and top-down attentional control. Neuroscience 2008;152:381-90.

[138] Bentley P, Vuilleumier P, Thiel CM, Driver J, Dolan RJ. Cholinergic enhancement modulates neural correlates of selective attention and emotional processing. Neuroimage 2003;20:58-70.

[139] Bentley P, Husain M, Dolan RJ. Effects of cholinergic enhancement on visual stimulation, spatial attention, and spatial working memory. Neuron 2004;41:969-82.

[140] Bentley P, Driver J, Dolan RJ. Modulation of fusiform cortex activity by cholinesterase inhibition predicts effects on subsequent memory. Brain 2009;132:2356-71. 
[141] Winterer G, Musso F, Konrad A, Vucurevic G, Stoeter P, Sander T, et al. Association of attentional network function with exon 5 variations of the CHRNA4 gene. Hum Mol Genet 2007;16:2165-74.

[142] Xu J, Mendrek A, Cohen MS, Monterosso J, Simon S, Brody AL, et al. Effects of acute smoking on brain activity vary with abstinence in smokers performing the $N$-back task: a preliminary study. Psychiat Res: Neuroim 2006;148:103-9.

[143] Ernst M, Matochik JA, Heishman SJ, Van Horn JD, Jons PH, Henningfield JE et al. Effect of nicotine on brain activation during performance of a working memory task. Proc Natl Acad Sci USA 2001;98:4728-33.

[144] Kumari V, Gray JA, Ffytche DH, Mitterschiffthaler MT, Das M, Zachariah E, et al. Cognitive effects of nicotine in humans: an fMRI study. Neuroimage 2003;19:1002-13.

[145] Dumas JA, Saykin AJ, McDonald BC, McAllister TW, Hynes ML, Newhouse PA. Nicotinic versus muscarinic blockade alters verbal working memory-related brain activity in older women. Am J Geriatr Psychiatry 2008;16:272-82.

[146] Furey ML, Pietrini P, Haxby JV. Cholinergic enhancement and increased selectivity of perceptual processing during working memory. Science 2000;290:2315-9.

[147] Schon K, Atri A, Hasselmo ME, Tricarico MD, LoPresti ML, Stern CE. Scopolamine reduces persistent activity related to long-term encoding in the parahippocampal gyrus during delayed matching in humans. J Neurosci 2005;25:9112-23.
[148] Chuah LYM, Chong DL, Chen AK, Rekshan WR, Tan JC, Zheng H, et al. Donepezil improves episodic memory in young individuals vulnerable to the effects of sleep deprivation. Sleep 2009;32:999-1010.

[149] Kukolja J, Thiel CM. Fink GR. Cholinergic stimulation enhances neural activity associated with encoding but reduces neural activity associated with retrieval in humans. J Neurosci 2009;29:8119-28.

[150] Sperling R, Greve D, Dale A, Killiany R, Holmes J, Rosas HD, et al. Functional MRI detection of pharmacologically induced memory impairment. Proc Natl Acad Sci USA 2002;99:455-60.

[151] Bozzali M, MacPherson SE, Dolan RJ, Shallice T. Left prefrontal cortex control of novel occurences during recollection: a psychopharmacological study using scopolamine and event-related fMRI. Neuroimage 2006;33:286-95.

[152] Rosier AM, Cornette L, Dupont P, Bormans G, Mortelmans L, Orban GA. Regional brain activity during shape recognition impaired by a scopolamine challenge to encoding. Eur J Neurosci 1999;11:3701-14.

[153] Thiel CM, Henson RNA, Dolan RJ. Scopolamine but not lorazepam modulates face repetition priming: a psychopharmacological fMRI study. Neuropsychopharmacol 2002;27:282-92.

[154] Mentis MJ, Sunderland T, Lai J, Connolly C, Krasuski J, Levine B, et al. Muscarinic versus nicotinic modulation of a visual task. A pet study using drug probes. Neuropsychopharmacology 2001;25:555-64.

[155] Knight RT. Neural networks debunk phrenology. Science 2007;316:1578-9. 